\title{
A ABORDAGEM TERRITORIAL NO PLANEJAMENTO DE POLÍTICAS PÚBLICAS E OS DESAFIOS PARA UMA NOVA RELAÇÃO ENTRE ESTADO E SOCIEDADE NO BRASIL
}

\section{A TERRITORIAL APPROACH TO THE PLANNING OF PUBLIC POLICIES AND THE CHALLENGES FOR A NEW RELATIONSHIP BETWEEN STATE AND SOCIETY IN BRAZIL}

\begin{abstract}
RESUMO
Este trabalho tem como principal objetivo analisar as inovações institucionais e as contradições inseridas na abordagem territorial para o planejamento e implementação de políticas públicas no Brasil. A partir de 2003, surgiram vários programas elaborados no âmbito do governo federal com base em uma perspectiva territorial. De maneira geral, esses programas têm em comum: definir um recorte espacial para sua atuação, priorizar áreas de concentração de pobreza, atuar de forma descentralizada e priorizar instâncias coletivas de deliberação e participação social. Porém, persistem alguns entraves para uma consolidação e institucionalização de fato da abordagem territorial para a ação estatal no Brasil. Entende-se que a retórica discursiva presente nos documentos oficiais não foi acompanhada por inovações normativas que a legitime. Por outro lado, as experiências em curso já desencadearam bons resultados, como a formação de novos arranjos institucionais locais e a maior aproximação entre atores sociais e a gestão de políticas e projetos territoriais.
\end{abstract}

PALAVRAS-CHAVE Políticas públicas, planejamento governamental, territórios de incidência, participação social, desenvolvimento territorial.

\section{Sandro Pereira Silva sandro.pereira@ipea.gov.br}

Graduado e mestre em Economia pela Universidade Federal de Viçosa (UFV)

Doutorando em Ciências Sociais pela Universidade de Brasília (UnB)

Técnico de planejamento e pesquisa do Instituto de Pesquisa e Planejamento Econômico (IPEA)

Artigo submetido no dia 03.11.2011 e aprovado em 23.06.2012

\begin{abstract}
The main objective of this research is to analyze the institutional innovations and contradictions embedded in the territorial approach to the planning and implementation of public policies in Brazil. Since 2003, there were several programs established under the federal government based on a territorial perspective. In general, these programs have in common: to define a spatial area for its action, to prioritize areas of concentrated poverty, to work in a decentralized manner and to prioritize instances of collective deliberation and participation. However, there remain some barriers to consolidation and institutionalization of the territorial approach to state action in Brazil. It is understood that the discursive rhetoric in official documents was not accompanied by innovations in rhythm normative legitimacy. On the other hand, the current experiments have triggered good results, as the formation of new institutional arrangements and closer relations between local actors and social policy management and territorial projects.
\end{abstract}

KEYWORDS Public policy, government planning, territories of incidence, social participation, territorial development. 


\section{SANDRO PEREIRA SILVA}

\section{INTRODUÇÃO}

A década de 1980 foi marcada por profundas mudanças no ambiente político brasileiro que vieram a definir um novo quadro de atuação do Estado. Tais mudanças derivam do ressurgimento do ativismo civil a partir dos anos 1970, na sua busca por autonomia frente ao Estado autoritário constituído em 1964, o que alguns autores caracterizam como a fundação efetiva da sociedade civil no Brasil (DAGNINO, 2002). Os dois pontos fundamentais que marcaram esse período de mudanças foram: 1) a volta ao Estado democrático de direito após vinte anos de governo militar no país, entre 1964 e 1984, que permitiu a legalização, reorganização e atuação dos diferentes grupos e movimentos sociais; e 2) a promulgação da Constituição Federal do Brasil, em 1988, que institucionalizou uma série de direitos sociais e garantiu a democracia como um princípio básico da ação política nacional.

Como consequência desses acontecimentos e de todo um contexto político e econômico internacional, a década de 1990 marcou o início dos debates em torno da reforma administrativa do Estado brasileiro, que viria a definir as principais diretrizes da atuação governamental no território nacional. Dois fenômenos importantes ganharam destaque nesse cenário. $\mathrm{O}$ primeiro refere-se à tendência à descentralização administrativa das políticas públicas, no contexto do pacto federativo, com o município passando a exercer um papel mais estratégico. O segundo diz respeito à garantia de uma maior participação da população, seja no planejamento, implementação ou avaliação dessas políticas, tanto diretamente como por meio de suas organizações representativas. A participação social passou a ser considerada, por um lado, um dos elementos fundamentais do projeto de ressignificação do conceito de público, e por outro, um princípio político-administrativo, com vistas a um maior controle e eficácia dos serviços prestados (MILANI, 2008).

No entanto, os antigos instrumentos de planejamento estatal não eram mais compatíveis com esse novo cenário político-institucional, que exigia políticas públicas efetivas aliadas à garantia de controles democráticos. Como o Brasil compreende uma complexa diversidade ambiental, cultural e econômica, convivendo com desigualdades sociais históricas, era necessária a definição de uma abordagem que permitisse e valorizasse as forças sociais locais na definição de suas prioridades. Além disso, a literatura sobre a temática regional no país já destacava a forte heterogeneidade das macrorregiões brasileiras, que as tornava inadequadas para servirem como referência exclusiva para ações de desenvolvimento regional (BANDEIRA, 2007).

Foi a partir desse contexto que, nos anos finais de 1990, o governo federal passou a considerar a definição de novas escalas para o planejamento de suas intervenções, tendo como influência todo o acúmulo da abordagem territorial em curso em vários países da União Europeia. Essa abordagem considera o território, definido com base em múltiplas dimensões, como o espaço de mediação social e de incidência de políticas públicas (SILVA, 2008), e, portanto, lócus privilegiado para o planejamento estatal. Assim, surgiu no Brasil uma série de políticas públicas, nos últimos dez anos, ancoradas em uma abordagem territorial, cada uma com seu enfoque, seus recortes territoriais e seus arranjos institucionais específicos. Diversas instâncias colegiadas (fóruns, conselhos, etc.), envolvendo representantes do poder público e da sociedade civil, foram constituídas no desenho dessas políticas como instâncias de deliberação, denominadas genericamente por Dagnino (2002) "espaços públicos".

Parte-se dessa discussão acima para apresentar a seguinte indagação: quais as inovações trazidas pela abordagem territorial nas relações entre Esta- 
do e sociedade civil no contexto do planejamento e implementação de políticas públicas no Brasil? Trata-se de compreender os avanços e contradições na condução desse novo paradigma de intervenção estatal, com seus métodos, instrumentos e procedimentos, ou seja, o foco de análise está mais nos mecanismos de governança estabelecidos pelas políticas do que em seu conteúdo propriamente dito.

Para tanto, utilizou-se de uma revisão da literatura (teórica e empírica) existente que aborda essa temática sobre diferentes prismas, além de uma análise documental sobre os principais programas em curso no Brasil ancorados sob o enfoque territorial, disponibilizados pelos ministérios responsáveis (leis, notas técnicas, publicações, editais, etc.). Foram escolhidos quatro programas para análise: a Política Nacional de Desenvolvimento Regional (PNDR); os Consórcios de Segurança Alimentar e Desenvolvimento Local (CONSADs); o Programa Nacional de Desenvolvimento Territorial Sustentável (PRONAT); e o Programa Territórios da Cidadania (PTC). A escolha desses programas, entre outros em andamento, se deve à maior dimensão, tanto em termos de peso político no âmbito do governo federal quanto em parcela do território nacional que eles abrangem.

\section{SOBRE O CONCEITO DE TERRITÓRIO}

O termo "território" perpassa pelos mais diversos ramos das ciências sociais, em cada um contendo particularidades próprias que definem sua abrangência. Enquanto conceito, assume formas e conteúdos diversos, sempre revestido do interesse em explicar uma realidade de relações complexas entre os distintos atores sociais ${ }^{1}$ e destes com o seu meio.

A primeira concepção surgiu basicamente sob uma visão naturalista, onde o território foi enten- dido como imperativo funcional, um elemento da natureza inerente a um povo ou nação, pelo qual se deve lutar para conquistar ou proteger. Essa visão delimitou o campo de estudo da geografia tradicional, diferenciando-a de outras ciências, e teve como um de seus principais precursores o alemão Friedrich Ratzel, com sua obra Geografia política, publicada em 1897. Ratzel entendia o território similarmente à ideia de hábitat, usada na biologia para a delimitação de áreas de domínio de uma determinada espécie ou grupo de animais. A noção de espaço estava implícita na sua análise, ao identificar o território como um substrato para a efetivação da vida humana, que tanto existiria sem a presença do homem (apolítico) como com a presença deste e sob domínio do Estado (político). Com isso, Ratzel trouxe uma importante contribuição ao vincular o território como imprescindível para a constituição do Estado-Nação e para a manutenção e conquista de poder, e seus conceitos deram suporte à constituição da geopolítica (CANDIOTTO, 2004; PERICO, 2009).

Ao longo do século XX, as profundas mudanças que foram ocorrendo na geografia trouxeram também novas abordagens para o conceito de território. O francês Claude Raffestin contribuiu valiosamente ao mostrar como a geografia política clássica desde Ratzel foi trabalhada simplesmente como uma "geografia do Estado", não abstraindo outras formas de poder. Assim, Raffestin (1993) destacou a ideia de poder que passou a ser assumida em suas diversas origens e manifestações, mas sempre focando sua projeção no espaço. O próprio uso e transformação dos recursos naturais se configuram como instrumentos de poder, o que ressalta a consideração da natureza como elemento presente no território. O autor também buscou diferenciar conceitualmente espaço e território. Para ele, o espaço está relacionado ao patrimônio natural existente em uma região definida, enquanto o território abrange a apropriação 


\section{SANDRO PEREIRA SILVA}

do espaço pela ação social de diferentes atores. Assim, o território incorpora o jogo de poder entre os atores de um determinado espaço.

Outro autor importante na formação do conceito de território é Robert Sack. Ele trabalhou a ideia de território em um nível mais concreto, e sua noção de territorialidade possui um alcance mais limitado, entendida como a qualidade necessária para a constituição de um território. Sack (1986) incorporou a noção de territorialidade à de espaço ao destacar a dimensão política e o simultâneo papel das fronteiras na definição de estratégias de dominação, buscando examinar o território na perspectiva das motivações humanas. Para ele, o território constitui expressão de um espaço dominado por um grupo de pessoas que fazem uso desse domínio para manter controles e influências sobre o comportamento de outros, exercendo relações de poder. Para ele, a territorialidade é o próprio "meio pelo qual espaço e sociedade estão inter-relacionados", com todas as suas dimensões de sociabilidade (p. 5).

Das contribuições na literatura brasileira, o principal teórico foi o geógrafo Milton Santos. Ele desenvolveu seu pensamento a partir de uma base materialista histórica e da dialética marxista para expressar a historicidade derivada da conjugação entre a materialidade territorial e as ações humanas, isto é, trabalho e política. Em sua teoria, o território traz em si a ideia de território usado, que é construído e constituído por uma população e caracterizado por suas estruturas sociais, econômicas e produtivas, ou seja, as ações espacializadas dos atores sociais (SANTOS; SILVEIRA, 2001). O autor partiu de uma perspectiva inversa em relação aos autores citados anteriormente e afirmou que "um Estado-Nação é essencialmente formado de três elementos: 1 . O território; 2. Um povo; 3. A soberania. A utilização do território pelo povo cria o espaço. As relações entre o povo e seu espaço e as relações entre os diversos territórios nacionais são reguladas pela função da soberania" (SANTOS, 1978, p. 189).

De acordo com Santos (1997), a noção atual de território apresenta novos recortes, além da velha categoria de região, o que denomina horizontalidades e verticalidades. O primeiro recorte diz respeito à continuidade territorial entre espaços e lugares vizinhos (não de contiguidade). O segundo é formado por pontos distantes uns dos outros, mas que são conectados por uma miríade de formas e processos sociais (noção de interconectividade). Sob esse entendimento, o território é formado de lugares contíguos (vizinhança) e de lugares em rede (processos sociais que ligam lugares diferentes), mas que contêm, simultaneamente, funções diferentes e até opostas, criando novas solidariedades, mesmo no contexto das diferenças entre as pessoas e entre os lugares.

A partir dos trabalhos desses autores, diversos outros pesquisadores se debruçaram para definir uma abordagem mais atual e instrumentalizada do conceito de território que consiga expressar a multidimensionalidade que ele envolve. Perico (2009), reportando-se a Haesbaert (2004), fez um breve resumo do uso desse conceito em diferentes áreas do conhecimento. Segundo o autor, na visão jurídica, o território é definido como espaço delimitado e controlado pelo exercício do poder sob a concepção mais subjetiva - cultural e simbólica; constitui produto da apropriação e valorização simbólica de um grupo em relação ao espaço sentido, vivido e compartilhado. Sob a concepção econômica, o território evoca a dimensão das restritas relações econômicas, que o concebe como sinônimo de recursos, da relação capital-trabalho ou da divisão "territorial" do trabalho. Já a concepção naturista enfatiza as relações homem/natureza/sociedade, manifestada em sua relação ambiental. Por último, "o território é usado na perspectiva de desenvolvimento e considerado variável nas políticas de intervenção sobre o espaço e as populações que buscam mudanças no marco das relações sociais e econômicas" 
(PERICO, 1997, p. 57).

Assim, para fins deste trabalho, pode-se estabelecer uma definição sintética de território como um espaço de construção histórica e social, de poder instituído (porém não imutável), caracterizado por recursos físicos (naturais e industriais) e valores (históricos e culturais), que estabelece uma relação de identidade ao corpo social que nele habita.

\section{POLÍTICAS E PLANEJAMENTO TERRITORIAL NO BRASIL}

O debate sobre o planejamento da ação governamental no Brasil precisa levar em conta algumas realidades que, ao mesmo tempo que tornam a temática bastante complexa, revestem-na de necessidade. Em termos institucionais, persistem no país duas escalas territoriais relevantes para o planejamento: uma que apresenta institucionalização "forte" - a dos estados e dos municípios; e outra com institucionalização mais "fraca e incompleta" - a das macrorregiões (BANDEIRA, 2007). Entre essas diferentes escalas, observa-se um cenário de forte desigualdade socioeconômica que se arrasta historicamente até os dias atuais. Por outro lado, observa-se também uma magnífica diversidade regional de ecossistemas, culturas e saberes, que se configura em um enorme potencial de desenvolvimento endógeno (ARAÚJO, 2007).

A ação deliberada de planejamento estatal teve um marco importante com a criação do Ministério do Planejamento em 1962, no governo de João Goulart. O primeiro ministro a assumir a pasta foi o economista Celso Furtado, reconhecido internacionalmente por seu trabalho como professor na França, sua atuação na Comissão Econômica para a América Latina e Caribe (Cepal) nos anos 1950 e por seus escritos sobre a economia latino-americana. Suas teses funda- mentaram as principais ações governamentais de planejamento econômico naquela época e ainda persistem como referências importantes. Em sua obra, Furtado não acreditava no subdesenvolvimento como uma etapa para o desenvolvimento (visão "etapista"), mas sim como uma característica estrutural permanente (visão "estruturalista"). Nesse sentido, ele partiu de uma abordagem histórico-estruturalista para determinar os mecanismos da dependência que envolvia esses países na divisão internacional do trabalho, bem como seus desdobramentos na estrutura social interna.

Furtado (1974) confiava no processo político para reverter esse quadro perverso de dependência, que gerava desigualdades extremas no território brasileiro e era, a seu ver, responsável pelo subdesenvolvimento do país. Ele ponderava, entre outros pontos, dois em especial: a introdução do planejamento como um instrumento guia para o governo, cujas funções na área econômica provavelmente se expandirão à medida que a luta para superar o subdesenvolvimento se torna mais intensa; e o fortalecimento das instituições da sociedade civil (principalmente os sindicatos), para ampliarem as bases sociais subjacentes ao Estado e se oporem aos padrões existentes de distribuição de renda. Entre as principais ações defendidas pelo autor no plano prático estavam: a substituição de importações e a reforma agrária.

A questão do desenvolvimento regional também esteve fortemente presente na obra de Furtado. Para ele, um "processo de integração teria de orientar-se no sentido do aproveitamento mais racional de recursos e fatores no conjunto da economia nacional" (FURTADO, 2003, p. 249). A principal ação prática no sentido de reorganização do espaço econômico regional e sua integração nacional foi viabilizada ainda no governo de Juscelino Kubitschek, em 1959, com a criação da Superintendência de Desenvolvimento do Nordeste (Sudene), como proposta para coordenar um projeto de desenvolvimento do Nordeste, re- 


\section{SANDRO PEREIRA SILVA}

gião com maiores índices de pobreza e deficiências estruturais do país. Embora a Sudene tenha sofrido posteriormente, sobretudo após 1964, deturpações no seu projeto original, o debate em torno do planejamento regional para a ação governamental persistiu. Porém, diferentes autores apontam críticas à base de referência regional brasileira atual, quando, na realidade, existe uma diversidade de padrões territoriais e regionais presentes na definição e na função de cada núcleo de convívio.

Brandão (2007) é um dos autores a abordar a questão do estabelecimento de escalas regionais apropriadas para a elaboração de políticas públicas. Para ele, as políticas de desenvolvimento com maiores e melhores resultados são aquelas que não discriminam nenhuma escala de atuação e reforçam as ações multiescalares: microrregionais, mesorregionais, metropolitanas, locais, entre outras, contribuindo para a construção de escalas espaciais analíticas e políticas adequadas a cada problema concreto a ser diagnosticado e enfrentado.

Para Perico (2009), o planejamento de políticas públicas deve levar em conta alguns fatores que irão diferenciá-las entre si. Por um lado, elas se diferenciam em relação a sua matéria de tratamento (educação, saneamento, saúde, habitação, etc.), que a definirá enquanto uma política setorial. Por outro lado, as políticas diferem pelo âmbito de sua cobertura, a ser definido pelos gestores e organismos responsáveis, sobretudo quanto ao público a ser beneficiado, quais os critérios de inclusão e, em alguns casos, defini-se também as localidades de sua execução. Assim, a abordagem territorial para o planejamento de políticas públicas auxilia no entendimento dos fenômenos sociais, contextos institucionais e cenários ambientais sob os quais ocorrerá a intervenção desejada, de maneira a propiciar meios mais acurados para a definição e alcance de metas, parcerias necessárias e instrumentos de implementação.
A abordagem territorial abrange as escalas dos processos de desenvolvimento e implica um método para favorecê-lo - reconhecendo não ser resultado de uma ação verticalizada do poder público - a partir de condições criadas para mobilizar os agentes locais para atuarem em termos de visão futura, elaborar diagnóstico de suas potencialidades e limitações (que contemple os próprios meios para se obter o desenvolvimento sustentável). Assim, a perspectiva territorial permite formular uma proposta centrada nas pessoas que consideram a interação dos sistemas socioculturais e ambientais e que contemplam a integração produtiva e o aproveitamento competitivo de seus recursos como meios que possibilitam a cooperação e a corresponsabilidade dos atores sociais pertencentes ao território (PERICO, 2009, p. 48).

Mendes (2008) afirmou que o reconhecimento do território como um instrumento central para a orientação de uma ação pública coordenada é uma postura inovadora na condução das políticas públicas contemporâneas, capaz de auxiliar a solucionar entraves históricos ao desenvolvimento nacional. $\mathrm{O}$ autor destacou também que a importância analítica do território vai além de um mero palco das ações políticas, pois representa em si próprio um elemento das relações sociais e econômicas globais.

Com base nesse entendimento, o território constitui uma base flexível sobre a qual agem diversas forças endógenas e exógenas, de forma que ele se encontra continuamente submetido a pressões de mudanças, conflitos e relações de poder que podem implicar em expansão ou deslocamento. Essas pressões expõem a importância de se manter a "integridade fundamentalmente social do território" (RODRIGUES, 2005, p. 46).

A temática territorial permitiu ainda a emergência de um discurso de revalorização do meio rural na definição de políticas públicas, com base em dois importantes postulados (ABRAMOVAY, 2003). O primeiro refere-se ao caráter multifuncional da agricultura, sobre o qual o meio rural deixa de ser entendido somente por suas 
características produtivas e passa a ser valorizado também por seus aspectos sociais, culturais e ambientais, embora a atividade produtiva agropecuária permaneça como atividade nuclear de seu espaço (MALUF, 2001). O segundo está relacionado a um posicionamento contrário à dicotomia rural-urbano, que negligencia as relações sociais que são desenvolvidas na prática em decorrência dos diversos mecanismos de integração do rural com o urbano. Essa interligação é denominada por Favareto (2007, p. 22) "dinâmicas territoriais de desenvolvimento". Para uma intervenção sobre essas dinâmicas, o autor realçou a necessidade de entender as articulações entre suas formas de produção e as características morfológicas dos tecidos sociais locais, a partir do entendimento de suas relações de "oposição e complementaridade".

Uma das motivações para a adoção da abordagem territorial nas políticas públicas refere-se à constatação das limitações do município em gerir programas governamentais estratégicos, que muitas vezes exigem a ampliação das ações para além de seus limites políticos. Como exemplos de ações dessa natureza, podem-se citar: projetos ambientais de recuperação de áreas degradadas, gestão de bacias hídricas, arranjos produtivos locais, entre outros (ALVES, 2007).

Para Sabourin (2002), o planejamento das ações de Estado sob uma ótica territorial envolve três desafios de grande relevância na atualidade: i) estabelecer ações que garantam uma representação democrática e diversificada da sociedade, a fim de que os diferentes grupos de atores possam participar mais ativamente das tomadas de decisão e ter mais acesso à informação; ii) realizar ações de capacitação junto aos atores locais para que possa ser formada uma visão territorial de desenvolvimento, rompendo a visão setorial como a única forma de análise; e iii) estabelecer novas formas de coordenação das políticas públicas, no que se refere aos recursos, às populações e aos territórios, baseadas em novas lógicas de desenvolvimento.

Em termos de mecanismos de garantia da participação social, a abordagem territorial segue a tendência da descentralização das políticas públicas por meio da criação de espaços públicos institucionalizados para a definição de prioridades e acompanhamento das ações propostas. $\mathrm{O}$ objetivo é ir além da formação de instâncias municipais de colaboração entre diferentes atores sociais, como nos casos dos Conselhos Municipais de Saúde ou Educação, e constituir instâncias de representação intermunicipal ou territorial, no sentido de democratizar as relações de poder na sociedade (CORREA, 2009).

Esses espaços de deliberação são vistos como laboratórios de construção coletiva para a negociação de consensos, por serem espaços "dialogicamente interativos e discursivamente mediados" (COELHO, 2005, p. 87), estabelecendo uma ligação política institucionalizada entre os atores locais, o que permite um processo democrático nas decisões. Porém, as relações de mediação não são necessariamente harmoniosas. Muitas vezes elas se desenvolvem em verdadeiras "arenas de conflito", sobretudo quando se encontram na pauta de discussão temas de caráter polêmico e que causam divergência de interesses. Nesses casos, a "partilha de poderes entre representantes de esferas sociais diversas nas decisões acerca da política pública é um de seus objetivos fundamentais" (LEITE et al., 2008, p. 77).

Mas o caráter conflituoso desses espaços não pode ser negligenciado. Para muitos atores sociais, esses fóruns são espaços importantes de formação política, ou, em outras palavras, de "aprendizado em negociação de interesses" (ROVER, 2011, p. 149). Assim, o sentido de participação nesse tipo de instância pode pender tanto para um "espaço de negociação de projetos e políticas" como para uma "arena de disputa e contestação", de forma que essa diferença seja entendida como um des- 
dobramento da dinâmica participativa instaurada em cada uma das diferentes instâncias (COELHO; FAVARETO, 2007). Ou seja, "a dinâmica da esfera participativa é resultado dessas duas dimensões: de suas leis (instituições) e de sua dinâmica interna; e de suas injunções com outras esferas do mundo social" (COELHO; FAVARETO, 2007, p. 122).

Com base na literatura apresentada, a abordagem territorial pode ser entendida como um novo paradigma de referência ao planejamento da ação pública na medida em que se constitui como um modelo para representar uma determinada realidade regional, socioeconômica e político-institucional, ou seja, o contexto no qual vivem as pessoas, as entidades governamentais, as empresas e demais organizações existentes. Segundo Moraes e Louro (2003, p. 31):

Quando se constrói um paradigma o que se busca fazer é oferecer ao planejador um conjunto de referências que permitam não apenas ver como também explicar e definir a configuração e o comportamento de um determinado fenômeno ou situação, mais ou menos complexa. Assim, a finalidade principal do paradigma é permitir que se possa chegar a entender tal fenômeno ou situação em seu conjunto e em suas partes, pela simplificação e redução de suas componentes.

Nesses termos, torna-se importante avaliar as principais características e encaminhamentos das experiências em curso, por parte do governo federal, de programas que partem dessa abordagem para sua implantação.

\section{EXPERIÊNCIAS RECENTES DE PLANE- JAMENTO TERRITORIAL NO BRASIL}

Uma das principais referências atuais para a implementação de estratégias de planejamento ter- ritorial é o Programa de Ligações entre Ações do Desenvolvimento da Economia Rural (LEADER). Esse programa surgiu no contexto da União Europeia em 1991, tendo como principal objetivo apresentar um enfoque multisetorial e integrado para a dinamização de espaços rurais com base em projetos territoriais inovadores.

Entre as principais características do programa LEADER estão: atuação em territórios definidos por áreas rurais pequenas e homogêneas; amplo incentivo à participação coletiva, com o envolvimento de atores públicos e privados; promoção da integração vertical de diferentes níveis institucionais; promoção de ações integradas, inovadoras e multisetoriais, enfatizando os recursos específicos locais; e estímulo a intercâmbios de experiências e de colaboração. Os grupos de ação local são os responsáveis pela definição dos territórios do LEADER, que contam com uma ampla e diversificada rede política, composta por agências de governo, sindicatos, organizações do setor privado, ONGs e representantes locais eleitos (SARACENO, 2005).

No contexto dos países da América Latina, a utilização desse enfoque ainda é muito incipientes. No Brasil, somente a partir dos anos finais da década de 1990 é que a temática territorial começou de fato a ganhar espaço no campo das políticas públicas, sobretudo com a emergência de uma maior descentralização administrativa na gestão de políticas públicas nacionais.

Bandeira (2007, p. 202) assinalou dois fatos como marcos importantes para a emergência da dimensão territorial no contexto das políticas públicas brasileiras. O primeiro deles refere-se à tentativa de abordar a problemática macroterritorial do desenvolvimento brasileiro na elaboração do Plano Plurianual 2000-2003, que usou como referência o estudo dos Eixos Nacionais de Integração e Desenvolvimento, realizado pelo governo federal. Já o segundo foi a própria criação do Ministério da Integração Nacional em 1999, que, de 
acordo com a Medida Provisória no 1.911/1999, possui entre suas competências as de: "formular e conduzir a política de desenvolvimento nacional integrada"; "formular os planos e programas regionais de desenvolvimento"; e "estabelecer estratégias de integração das economias regionais".

Em 2000, o Ministério da Integração Nacional elaborou o documento Bases para as Políticas de Integração Nacional e Desenvolvimento Regional, o qual propunha uma série de objetivos amplos para a gestão do território, tais como: promover a competitividade sistêmica; mobilizar o potencial endógeno de desenvolvimento das regiões; fortalecer a coesão econômica e social; promover o desenvolvimento sustentável; e fortalecer a integração continental. Em 2003, o governo federal, por meio da Lei $n^{\circ} 10.683$, conferiu a responsabilidade sobre o ordenamento territorial aos ministérios da Integração Nacional e da Defesa. Já em 2006, o Ministério da Integração Nacional apresentou os subsídios para a elaboração da proposta da Política Nacional de Ordenamento Territorial (PNOT).

Concomitantemente a todo esse debate, surgiram vários programas elaborados no âmbito do governo federal com base em uma perspectiva territorial. As primeiras propostas surgiram no governo do presidente Fernando Henrique Cardoso, no final dos anos 1990. Uma delas foi o Programa Comunidade Ativa, criado com o objetivo básico de combater a pobreza e promover o desenvolvimento por meio da indução do Desenvolvimento Local Integrado e Sustentável (DLIS). Esse programa propunha a formação de consórcios intermunicipais com o apoio do Serviço Brasileiro de Apoio às Micro e Pequenas Empresas (Sebrae). Já o Ministério de Ciência e Tecnologia introduziu no seu planejamento uma linha de atuação territorial para promover o desenvolvimento de Arranjos Produtivos Locais (APLs), entendidos como "aglomerados de agentes econômicos, políticos e sociais, localizados em um mesmo território, que apresentam vínculos consistentes de articulação, interação, cooperação e aprendizagem e vantagens microeconômicas advindas da proximidade entre os agentes" (GUANZIROLI, 2009, p. 3)

A partir de 2003, com o início da gestão do presidente Luiz Inácio Lula da Silva, abriu-se uma janela política para o surgimento de outros programas na agenda governamental (KINGDON, 1995). Em geral, esses programas objetivam incentivar a elaboração e implementação de projetos territoriais mediante um conjunto de regras definidas na esfera nacional.

Entre os principais programas em curso sob a abordagem territorial estão: a Política Nacional de Desenvolvimento Regional (PNDR); os Consórcios de Segurança Alimentar e Desenvolvimento Local (CONSADs); o Programa Nacional de Desenvolvimento Territorial Sustentável (PRONAT); e o Programa Territórios da Cidadania (PTC). É comum haver entre esses programas a sobreposição espacial na definição dos territórios para a intervenção de cada um deles, do tipo: os territórios se coincidirem; o território de um programa encontra-se contido no território de outro, de maior extensão; ou apenas alguns municípios de um território estão inseridos na delimitação territorial de outro programa. No entanto, Fernandes (2009, p. 206) não vê problemas quanto a essa questão, pois para ele os territórios são "utilizados de diferentes formas, assim como as pessoas assumem e executam distintas funções ou como as relações sociais se mesclam, gerando multiterritorialidades".

Dentre esses programas citados acima, o primeiro é a Política Nacional de Desenvolvimento Regional (PNDR), sob a gestão do Ministério da Integração Nacional (MI). Segundo seu marco institucional, a PNDR "define premissas, parâmetros e critérios básicos para a redução das desigualdades regionais no Brasil e estabelece uma tipologia sub-regional por microrregiões, a 


\section{SANDRO PEREIRA SILVA}

partir da qual o governo federal poderia orientar as ações a serem desenvolvidas", e surgiu como "instrumento de planejamento estatal com vistas à redução das desigualdades regionais, exposta como um dos objetivos fundamentais do Brasil pela Constituição de 1988". O foco das preocupações incide, portanto, na dinamização das regiões e na melhor distribuição das atividades produtivas pelo território nacional. Para Perico (2009), a instrumentalização da PNDR:

[...] evidencia a percepção sobre o manejo da escala regionale da territorialização brasileira. Seus principais programas e projetos são fortemente orientados por iniciativas de recorte espacial (territorial) a partir de critérios específicos. Ocorre o mesmo quanto aos instrumentos financeiros relativos aos Fundos Constitucionais (FCO, FNO e FNE), estabelecidos como matéria constitucional e destinados ao apoio de programas regionais de desenvolvimento (p. 45).

A PNDR trabalha com o conceito de mesorregião para seus recortes territoriais, sendo identificadas e homologadas inicialmente, pelo Ministério da Integração Nacional, 13 mesorregiões. Seus seguintes objetivos específicos são: a) dotar as regiões das condições necessárias de infraestrutura, crédito e tecnologia; b) promover a inserção social produtiva da população, a capacitação dos recursos humanos e a melhoria da qualidade de vida; c) fortalecer as organizações socioprodutivas regionais, ampliando a participação social; e d) estimular a exploração das potencialidades sub-regionais que advêm da diversidade socioeconômica, ambiental e cultural do país.

Para a definição de suas ações, a PNDR leva em consideração a presença de fortes desequilíbrios inter e intrarregionais. As regiões consideradas de alto rendimento concentram-se predominantemente no eixo sul-sudeste do país, enquanto nas regiões Norte e Nordeste persiste um quadro em que convergem baixos indicadores de renda e pouco dinamismo de sua base produtiva. Com base nesse cenário, as ações da PNDR constituem uma tentativa de diminuição das desigualdades existentes no Brasil. As principais ações são: o Programa de Desenvolvimento Integrado e Sustentável do Semiárido (Conviver); o Programa de Promoção da Sustentabilidade de Espaços Sub-Regionais (Promeso); o Programa de Organização Produtiva de Comunidades Pobres (Produzir); o Programa de Promoção e Inserção Econômica de Sub-Regiões (Promover); o Plano de Desenvolvimento Estratégico para o Semiárido (PDSA); o Plano de Desenvolvimento Sustentável para a Área de Influência da Rodovia BR-163; o Plano para a Amazônica Sustentável (PAS); o Programa de Desenvolvimento das Áreas de Fronteira (PDAF); e o Projeto de Integração do Rio São Francisco com as Bacias do Nordeste Setentrional.

Entre as estratégias de governança traçadas pela PNDR para alcançar seus objetivos, primeiramente é criado em cada mesorregião um fórum mesorregional como instrumento para a articulação institucional entre as diversas esferas de governo e organizações da sociedade civil. Os fóruns assumem uma função de destaque na concepção da PNDR, pois representam o eixo no qual as articulações se completam, tanto com vistas às atividades de planejamento e definição de prioridades (ações estratégicas) quanto para o acompanhamento e controle da execução de projetos e programas específicos (MORAES; LOURO, 2003).

Perico (2009) apontou a relevância da PNDR para abrigar o discurso do território na esfera do planejamento federal. No entanto, o autor disse haver certa confusão conceitual em seu estatuto na definição das diferentes escalas espaciais com as quais trabalha, tais como região e território. Além disso, como os recortes territoriais das mesorregiões são muito amplos, englobando inclusive diferentes estados em uma única mesorregião, torna-se muito difícil a coordenação e operacionalização de projetos conjuntos no interior dos 
territórios. Flores (2006) também chamou a atenção para a definição de territórios com largas dimensões. Segundo ele, as grandes diferenças de identidades dentro dos territórios dificultam tanto o estabelecimento de estratégias de valorização dos produtos, com base nas especificidades territoriais, como também a formação de arranjos institucionais locais para a execução de outras políticas públicas.

A segunda ação governamental citada trata dos Consórcios de Segurança Alimentar e Desenvolvimento Local (CONSADs), os quais configuram um desejo de estabelecer uma estratégia de cooperação entre o poder público e a sociedade civil para as iniciativas territoriais, projetos e ações estruturantes. Esse programa surgiu em 2003 para a promoção da segurança alimentar e do desenvolvimento local, inserido em uma ação maior do governo federal para o combate à fome e à pobreza no Brasil, que foi o Programa Fome Zero, sob responsabilidade do então recém-criado Ministério do Desenvolvimento Social e Combate à Fome (MDS).

Os CONSADs são arranjos territoriais em regiões de baixo índice de desenvolvimento que busca promover a cooperação entre os municípios. Em 2003, foram mapeados e constituídos pelo MDS, 40 CONSADs, com pelo menos um em cada estado brasileiro, que envolvem $585 \mathrm{mu}$ nicípios e uma população de mais de 11 milhões de habitantes. Os critérios de seleção dos municípios pelo MDS foram definidos com base no perfil socioeconômico, destacando também as carências infraestruturais e a presença de agricultura familiar nos municípios. Seu enfoque territorial abrange as seguintes dimensões:

a) as relações sociais, comerciais, produtivas, políticas e culturais existentes na região [...], b) a dimensão física e ambiental do território [...], c) as potencialidades geoestratégicas do território como base dos arranjos sócio-produtivos sustentáveis; d) a necessidade de reorganização do território de forma a proporcionar a inclusão social [...], e) [...] construção de uma institucionalidade capaz de mediar conflitos, agregar esforços e gerar sinergias de forma a direcionar o processo de integração territorial para os objetivos de segurança alimentar e nutricional e desenvolvimento local; f) fortalecimento da identidade territorial e a construção de um sentimento de solidariedade social (JESUS, 2006, p. 62).

As estratégias de intervenção dos CONSADs envolvem basicamente três linhas principais: 1) implementação de ações e políticas específicas de segurança alimentar; 2) articulação de iniciativas de competência de outras esferas de governo e instituições da sociedade civil; e 3) gestão participativa com vistas a tornar as comunidades protagonistas de seu processo de emancipação.

Os consórcios são concebidos como associações intermunicipais, sob orientação da Secretaria de Segurança Alimentar e Nutricional (SESAN/MDS), com o objetivo de congregar metas sociais do poder público e da sociedade civil para a promoção de ações conjuntas, com foco na segurança alimentar e no desenvolvimento sustentável. Eles são, portanto, uma forma de associação entre municípios, com participação da sociedade civil e do poder público, para ações conjuntas de geração de emprego e renda.

A ação consorciada parte da proposta de que a integração territorial é fundamental para melhorar as condições de inserção dos municípios empobrecidos e de pequeno porte na dinâmica do território nacional, provendo essas localidades de melhores condições de competitividade, solidariedade sistêmica e de maiores possibilidades para assegurarem $\mathrm{o}$ atendimento às necessidades básicas de seus munícipes. Por intermédio dos consórcios, pretende-se tornar permanente a articulação entre o poder público e a sociedade civil para a promoção de ações de desenvolvimento de forma institucionalizada (ORTEGA, et al., 2009, p. 5). 


\section{SANDRO PEREIRA SILVA}

Cada consórcio deve buscar o enfrentamento dos problemas de sua região e a alavancagem das potencialidades de cada município de maneira articulada, reunidos por laços de identidades sociais, culturais, ambientais e econômicas. Neles são escolhidos os membros que irão compor o Fórum do CONSAD, instância máxima deliberativa dentro consórcio e responsável pelas decisões políticas. Os agentes envolvidos têm a incumbência de promover uma articulação para a elaboração de um plano intermunicipal de desenvolvimento sustentável, baseado em um diagnóstico dos principais problemas dos municípios. Cada fórum deve respeitar dois pressupostos básicos: 1) refletir a pluralidade entre os múltiplos segmentos sociais existentes no território; garantir uma representação majoritária da sociedade civil ( $2 / 3$ dos membros), buscando estimular e fortalecer a organização social do território como protagonista nas decisões diversas (JESUS, 2006).

Outra ação governamental sob a estratégia de intervenção territorial é o Programa de Desenvolvimento Sustentável de Territórios Rurais (PRONAT), também iniciada em 2003 e incluída no Plano Plurianual de Aplicações (PPA) 2004-2007, sob a responsabilidade do Ministério do Desenvolvimento Agrário (MDA) e a coordenação de sua Secretaria de Desenvolvimento Territorial (SDT). O programa, centrado na inclusão e na justiça social, na reativação das economias locais e na gestão sustentável dos recursos naturais, foi concebido para ser implementado a longo prazo, alcançando todos os espaços rurais do Brasil, especialmente os que apresentem características de estagnação econômica, problemas sociais e riscos ambientais, com forte presença de agricultores familiares e assentados de reforma agrária (BRASIL, 2005) $)^{2}$.

De acordo com as diretrizes do MDA, o desenvolvimento rural, pensado de forma sustentável, tem como meta principal estimular e favorecer a coesão social e territorial das regiões e dos países onde ela é empregada como "elemento harmonizador" dos processos de ordenamento e de desenvolvimento da sociedade em geral. Para alcançar suas principais metas, assim como nos CONSADs e nos Fóruns Mesorregionais, um dos objetivos do PRONAT é articular atuações conjuntas com outros órgãos da administração federal, estadual e municipal, bem como da sociedade civil em geral. O conceito de território adotado define-se como:

[...] um espaço físico, geograficamente definido, geralmente contínuo, compreendendo cidades e campos, caracterizadoporcritériosmultidimensionais, tais como o ambiente, a economia, a sociedade, a cultura, a política e as instituições, e uma população, com grupos sociais relativamente distintos, que se relacionam interna e externamente por processos específicos, onde se pode distinguir um ou mais elementos que indicam identidade e coesão social, cultural e territorial (BRASIL, 2005, p. 28).

Esses elementos devem propiciar um sentimento de pertencimento aos diversos grupos locais espalhados pelos municípios que o compõem de forma a consolidar uma maior coesão social e territorial entre seus atores sociais. A caracterização geral da denominação "território rural" no âmbito do MDA, além das condições acima, tem por base as microrregiões geográficas que apresentam densidade demográfica menor que 80 habitantes por quilômetro quadrado e população média por município de até 50 mil habitantes, incluindo-se nesses territórios os espaços urbanizados que compreendem pequenas e médias cidades, vilas e povoados (BRASIL, 2005). Atualmente, o MDA atua em 164 territórios rurais, os quais compreendem um total de 2.392 municípios, com cerca de 47,1 milhões de habitantes, sendo 16,1 milhões residentes em áreas rurais. Esses territórios abrangem uma área de 52\% da superfície nacional.

Uma de suas principais inovações institucionais encontra-se na definição de suas áreas de 
resultado, que são quatro: articulação de políticas públicas; formação e fortalecimento de redes sociais; dinamização econômica de territórios rurais; e gestão social. Sobre as três primeiras, pode-se dizer que são comuns a qualquer outro programa de desenvolvimento local ou territorial. A novidade fica pelo fato de a gestão social estar entre as áreas de resultado do programa, deixando de ser considerada apenas como instrumento para se chegar aos resultados esperados. Ou seja, o fortalecimento da gestão social é por si só um resultado a ser alcançado.

Para fortalecer e garantir o processo de gestão social dos territórios rurais, são formados em cada um deles os Conselhos de Desenvolvimento Territorial Rural Sustentável (CODETER), que são espaços públicos compostos paritariamente por representantes do poder público local e sociedade civil. Esses colegiados surgem no sentido de dar um caráter mais amplo com relação aos já existentes Conselhos Municipais de Desenvolvimento Rural Sustentável (CMDRS), sem contudo substituí-los ou extingui-los. Os CODETERs são as instâncias maiores de deliberação no território, no que diz respeito a ações prioritárias de desenvolvimento rural sustentável, com o objetivo principal de compartilhar o poder de decisão e "empoderar" os atores sociais no sentido de desenvolver as habilidades coletivas necessárias (BRASIL, 2005). O orçamento do programa para os projetos territoriais também contempla recursos para a realização de oficinas, custeio das despesas para as assembleias gerais, além do pagamento de um assessor territorial, que é a principal personagem de referência no território.

O principal instrumento de planejamento e gestão social no território é o Plano Territorial de Desenvolvimento Rural Sustentável (PTDRS). Esse documento é elaborado conjuntamente por consultores contratados pelo MDA e atores sociais locais (agricultores familiares, gestores pú- blicos, representantes de ONGs, sindicatos, instituições de pesquisa, entre outras), a partir de metodologias participativas para o levantamento e problematização das informações e definição da visão de futuro do território.

Os projetos no âmbito do PRONAT são debatidos no interior dos CODETERs, devendo atender, por um lado, todos os critérios definidos anualmente pelo MDA, e por outro, os eixos estratégicos para o desenvolvimento territorial estabelecidos no PTDRS do território. Todos os projetos aprovados são encaminhados para o Conselho Estadual de Desenvolvimento Rural Sustentável (CEDRS), que avalia o mérito de cada projeto, podendo sugerir ajustes ou correções de acordo com as instruções normativas do PRONAT para aquele ano. Após a análise dos projetos, o CEDRS emite um parecer a ser encaminhado para o MDA, acompanhado de cópia da documentação requerida. Por sua vez, o MDA emite outro parecer técnico sobre o projeto, que, em caso de aprovação, será homologado e encaminhado à Caixa Econômica Federal, órgão responsável pela gestão financeira dos projetos.

Toda essa sequência para a apresentação e seleção dos projetos aponta que os proponentes estão sujeitos às normas que vêm de "cima para baixo". Outra grande preocupação é quanto às exigências burocráticas dos agentes financeiros, tidas por muitos atores envolvidos como os principais responsáveis pela paralisação dos projetos (FREITAS, 2011).

Em fevereiro de 2008, o programa de desenvolvimento territorial do MDA ganhou maior vulto institucional com o lançamento do Programa Territórios da Cidadania (PTC). Esse programa é administrado pelo governo federal, por meio do Ministério da Casa Civil, e envolve outros $21 \mathrm{mi}-$ nistérios e autarquias diferentes. Seu objetivo é garantir uma melhor focalização e articulação entre as ofertas de políticas públicas aos municípios 
de territórios elencados a partir de alguns critérios, como índice de pobreza, baixo IDH, existência de grande número de agricultores familiares e assentados de reforma agrária, etc. No primeiro ano foram escolhidos 60 territórios rurais entre aqueles já homologados pelo MDA, passando em 2009 para 120 territórios.

O governo federal definiu uma meta ambiciosa de 180 ações logo no seu início, organizadas em três eixos estruturantes: Apoio às atividades produtivas; Cidadania e direitos; e Infraestrutura. Por sua vez, esses eixos foram divididos em sete temas: Organização sustentável da produção; Ações fundiárias; Educação e cultura; Direitos e desenvolvimento social; Saúde, saneamento e acesso à água; Apoio à gestão territorial; e Infraestrutura, conforme demonstrado na Figura 1.

Segundo Corrêa (2009, p. 23), o PTC pode ser considerado um marco na estratégia de planejamento territorial de políticas públicas orquestrada

Figura 1 - Eixos e temas para as ações do Programa Territórios da Cidadania

\begin{tabular}{|l|l||}
\hline \multicolumn{1}{|c|}{ EIXOS } \\
•Apoio a atividades \\
produtivas
\end{tabular}

Fonte: Elaboração a partir de Ghesti (2011).

pelo governo federal, na medida em que busca articular o "direcionamento de recursos e programas oriundos de diferentes ministérios para os territórios eleitos como prioritários para receberem tais apoios", por isso foi colocado sob a coordenação do Ministério da Casa Civil. De acordo com a autora, a perspectiva é que as ações desenvolvidas articulem aspectos de propostas de políticas "de cima para baixo" (top-down), articuladas a projetos vindos das próprias comunidades que os recebem, ou "de baixo para cima" (bottom-up), visando um movimento de descentralização de decisões, de transversalidade ${ }^{3}$ de políticas e de contínua avaliação do direcionamento dos recursos.

Por outro lado, Corrêa (2009) chamou a atenção ao fato de que, ao mesmo tempo que o número de ministérios envolvidos é um indicador positivo, as várias ações propostas podem gerar dificuldades para o território poder gerir, articular e encaminhar os projetos necessários, dificultando 
a execução dos recursos. Com isso, os ministérios devem atentar a essa possibilidade e definir, na estrutura normativa de seus programas, recursos e instrumentos para auxiliar o trabalho dos atores locais na elaboração e consolidação dos projetos.

Deve-se deixar claro que o PTC não constitui um programa governamental propriamente dito, de acordo com a terminologia empregada no PPA. $\mathrm{Na}$ verdade, constitui uma estratégia de articulação de políticas públicas em recortes territoriais prioritários e predeterminados. Tampouco traz alguma inovação em termos de arranjos locais de governança e participação social, pois que faz uso da estrutura já constituída no arranjo do PRONAT. A única novidade foi a determinação para a inclusão de novos atores nos CODETERs, ligados aos demais temas referentes aos outros ministérios, como cultura, educação, gênero, etc. Com isso, os CODETERs foram incentivados a constituírem câmaras temáticas para o encaminhamento de ações e projetos setoriais, mantendo a assembleia geral como instância máxima de deliberação do território. Porém, não foram destinados novos recursos para essa maior mobilização social que o programa passou a demandar dos territórios, o que obrigou os atores locais a destinar uma parte de seu tempo dedicado à ação territorial para conseguir parcerias que auxiliem nos custos para a mobilização social.

Uma inovação que o PTC trouxe para sua execução em relação à forma anterior de organização do PRONAT foi a criação de um arranjo horizontal, no nível do governo federal, para articular as diferentes ações a serem inseridas na matriz do programa pelos órgãos que o compõem. Esse arranjo é composto pelos Comitês de Articulação Estaduais, de caráter consultivo, que auxiliam na intermediação da relação entre o Comitê Gestor Nacional e os CODETERs, no intuito de fortalecer a coordenação vertical.

Outra inovação definida no PTC foi o estabelecimento do Sistema de Gestão Estratégica (SGE), com base no entendimento de que os dados constituem informações fundamentais para o planejamento estratégico e para a qualificação da tomada de decisões (GHESTI, 2011). O SGE visa articular institucionalmente e operacionalmente um arranjo que envolve universidades, os Territórios Rurais e o próprio MDA nos respectivos processos de coleta, registro, acompanhamento, monitoramento, avaliação e análise de dados sobre os territórios. Nesse sentido, o MDA celebrou com o Conselho Nacional de Desenvolvimento Cientifico e Tecnológico (CNPq) em 2009 um termo de cooperação para o lançamento de um edital para a seleção de projetos de pesquisa e extensão tecnológica focados nos resultados do PRONAT. Esses projetos constituirão as chamadas Células de Acompanhamento das Informações Territoriais, funcionando como uma unidade operativa do SGE/MDA para a coleta, registro e análise de informações sobre os territórios.

Por outro lado, Favareto (2010) chamou a atenção para o fato de que, na prática, o programa permanece esbarrando em problemas antigos, frutos da forte tendência à setorização dos ministérios. Para o autor, os territórios são vistos por grande parte dos ministérios que o compõem como meros repositórios de investimentos, que consistem em ações já planejadas em programas dispersos. Ou seja, os gestores à frente dos ministérios não enxergaram o caráter estratégico do programa, da forma como desejava a princípio o governo federal, de forma que a maioria daqueles que ligaram suas ações ao PTC o fez por mera coerção da Casa Civil (algo que não ocorreu com os demais programas abordados neste texto), sem nenhuma readequação metodológica para contemplar a nova abordagem proposta de atuação territorial.

Esse fato instiga alguns questionamentos importantes sobre quais os principais entraves institucionais para a consolidação de propostas de planejamento e intervenção governamental a 
partir de uma estratégia diferenciada para a incidência territorial das políticas públicas. O próximo tópico traz um exercício analítico sobre essa questão, valendo-se das principais convergências e contradições encontradas no escopo institucional dos programas apresentados.

\section{CONVERGÊNCIAS ENTRE OS PRO- GRAMAS ESTUDADOS}

Com base na análise documental e na literatura empírica sobre os programas relatados acima, observou-se que o histórico das ações governamentais de planejamento territorial se fundamenta em uma crítica ao modelo tradicional de políticas públicas no país, sobretudo quando se observa a substituição do enfoque municipalista, de gestão autocrática ou centralista, por uma atuação intermunicipal, legitimada pelos agentes sociais locais. Eles buscam articular em suas engenharias institucionais, com vistas à maior incidência territorial das políticas públicas, as seguintes dimensões: a) politica: capacidades e competências para a gestão territorial; b) sociocultural: identidade e coesão social que facilitem as ações coletivas; e c) econômica: desenvolvimento e superação dos patamares de pobreza e desigualdade.

De maneira geral, os principais pontos normativos detectados entre os programas analisados neste texto têm em comum: definir recortes intermunicipais para sua atuação; priorizar áreas de baixa dinamização econômica e forte concentração de pobreza; buscar superar a dicotomia rural-urbano nos projetos de desenvolvimento; atuar de forma descentralizada e articulada com as três escalas de poder público; estimular a articulação entre demandas sociais e oferta de políticas públicas; partir da elaboração de um planejamento estratégico para o desenvolvimento do território; e priorizar instâncias coletivas de deliberação e participação social (espaços públicos), como os conselhos, fóruns, comitês, etc.

A superposição de territórios entre diferentes ministérios não se constitui em um problema maior, já que as escalas e as temáticas para a definição de cada tipo de território são diferentes. Por outro lado, a convergência dos vários espaços públicos criados em uma única instância de participação, organizada em câmaras temáticas de acordo com os interesses dos atores locais e das políticas ofertadas, poderia ser uma ação que permitisse um melhor fluxo de informações entre os atores envolvidos, o que reduziria o custo de transação ${ }^{4}$ da gestão dos projetos. O Programa Territórios da Cidadania almejou constituir um desenho dessa natureza, mas ainda não se têm relatos de sucessos alcançados nesse ponto.

O que se observa é que há uma tendência de que tanto as políticas públicas quanto os arranjos institucionais promovidos por elas sejam organizados em torno de questões setoriais tradicionais, o que Henriques (2011, p. 40) chamou de "isolacionismo setorial". Com isso, permanece a dificuldade para a construção de programas de natureza intersetorial que dialoguem com as várias dinâmicas (existentes ou potenciais) das economias territoriais. Na mesma linha de entendimento, Araújo (2007) afirmou que o viés setorial está muito impregnado na estrutura social brasileira e se reflete tanto nos diferentes níveis de governo como nas formas de organização da sociedade civil, o que a autora chamou de "camisa de força difícil de superar na construção do desenvolvimento territorial" (p. 204). Nesse ponto, apesar do esforço discursivo, os programas aqui analisados ainda não conseguiram avançar na construção desse ambiente intersetorial para a articulação de políticas públicas, o que demonstra que a abordagem territorial ainda requer tempo e modelos exitosos para ir se firmando. Mas, por outro lado, a cultura política da descontinuidade de programas, principalmente por conta do ciclo 
eleitoral no país, coloca-se como grande empecilho para a garantia de um tempo de maturação para uma estratégia dessa natureza, como ocorreu com a experiência europeia.

Verificou-se também que a extensão geográfica média dos territórios varia bastante tanto entre os programas como entre os territórios de um mesmo programa. Isso em parte se explica pelo fato de que a população não está dispersa de maneira homogênea em toda a extensão geográfica brasileira, havendo fortes disparidades regionais. Entende-se que esse fato, em si, não se constitui em um problema para os programas, desde que haja mecanismos em seu corpo normativo que possibilitem uma intervenção diferenciada de acordo com algumas especificidades predefinidas de seus territórios, o que não foi observado em nenhum dos programas.

Porém, chama-se a atenção para a necessidade de um cuidado especial na definição de territórios que encerram em seu espaço diferentes naturezas de desigualdade. Os limites socioeconômicos, simbólicos e políticos dos territórios, como lembrou Milani (2008), são obstáculos relevantes à participação, podendo inclusive aprofundar a desigualdade política no âmbito dos próprios dispositivos participativos. Nesse caso, o território pode ser apoderado por grupos dominantes e servir como instrumento de um aprofundamento consentido da desigualdade, fazendo-se valer da prerrogativa da participação social e autonomia local. Assim, diferentes segmentos sociais não conseguem ser representados nas instâncias deliberativas dos programas, passando a ser "invisibilizados" pelos grupos que comandam as definições nos territórios.

Para uma participação mais representativa e o fortalecimento da gestão social local, é necessário que os programas garantam investimentos próprios para isso, principalmente em ações de capacitação, assessoramento técnico e informações (ORTEGA, 2007), fato encontrado apenas no programa gerido pelo MDA. Ou seja, não se pode esperar que, em um passe de mágica, os atores locais marginalizados tomem para si o protagonismo do planejamento estratégico do território, sobretudo em regiões mais pobres, historicamente marcadas pela exclusão social e pelo domínio do poder local por pequenos grupos familiares. $\mathrm{O}$ aprendizado da ação política é um processo que demanda tempo e recursos.

Em termos de concepção dos programas, Ortega (2007) citou algumas deficiências importantes encontradas em sua pesquisa junto aos CONSADs que podem ser consideradas comuns aos demais programas analisados, tais como: dependência do ambiente macroeconômico, sobretudo em termos de política fiscal; minimização da estrutura das classes sociais e conflitos políticos locais; e desconsideração da inserção histórica na ordem capitalista dos diferentes territórios. Cita-se também o fato de que em nenhum deles a questão da concentração fundiária é tratada como um tema importante a ser levado para o debate, dado o fato de o Brasil apresentar uma concentração fundiária alta e permanente ${ }^{5}$. Temas conflituosos como reforma agrária e regularização fundiária aparecem apenas de maneira vaga e marginal, sem serem apontados os mecanismos concretos de viabilização.

Mas o principal limite entendido neste trabalho refere-se às questões legais quanto à institucionalização desses programas. Pode-se dizer que a evolução teórica e empírica da abordagem territorial e seus resultados em termos de planejamento de políticas públicas não foi acompanhada por inovações no marco jurídico brasileiro que permitissem uma maior dinamicidade e efetividade das políticas atuais formuladas a partir dessa abordagem. Embora os órgãos executores exijam a pactuação de projetos territoriais, a estrutura federalista brasileira não reconhece outra esfera administrativa passível de ser proponente de projetos federais estruturantes que não sejam 
os estados ou municípios. Nesse caso, os projetos passam a ter uma grande dependência das prefeituras municipais, de forma que mudanças de gestão próprias do ciclo político podem levar por terra toda uma pactuação previamente elaborada em nome de um projeto territorial. E como os processos eleitorais ocorrem de dois em dois anos no Brasil, essas pactuações se tornam frágeis por natureza, pois nada garante que os novos governantes honrarão os acordos firmados pelas administrações anteriores. Essa questão se reflete diretamente também na liberação do financiamento público. O que se observa é que as regras de gestão administrativa das contas públicas e a complexidade das dinâmicas estabelecidas por esses programas acarretam um tempo excessivo para a liberação dos recursos destinados à execução dos projetos aprovados nos territórios.

Ademais, nenhum dos programas explicita em seus marcos normativos os mecanismos pelos quais serão equalizadas as assimetrias de ordem técnica e institucional que caracterizam as unidades subnacionais da estrutura federativa brasileira. Sobre a questão do financiamento, não se constituiu até o momento nenhum instrumento novo que garantisse o apoio financeiro a projetos inovadores, com critérios claros e objetivos, que permitisse aos territórios maior autonomia para o planejamento e elaboração de seus projetos frente ao Executivo federal. Isso faz com que aumente também a dependência de recursos por meio de emendas parlamentares, que deturpam toda a estratégia participativa e dialogada da definição de prioridades, já que a ligação política dos parlamentares tende a passar por fora das instâncias colegiadas para a aprovação de seus projetos de interesse.

Em decorrência disso, as instâncias de governança local, criadas para atuarem na formulação, implementação e avaliação das políticas relevantes para o território, carecem de institucionalidade jurídica para seu reconhecimento enquanto unidades de gestão social. A Lei n ${ }^{\circ}$ 11.107/2005 possibilitou a constituição de consórcios intermunicipais (ou entre estados e municípios) com personalidade jurídica de direito público ou privado, no intuito de possibilitar novas relações horizontais cooperativas no âmbito regional e superar problemas de repasses de recursos. No entanto, além de não ser ainda um instrumento utilizado para constituir novas institucionalidades capazes de protagonizar ações territoriais de desenvolvimento, os consórcios públicos, por serem pessoas jurídicas formadas exclusivamente por entes da Federação, também dependem diretamente dos interesses dos governantes eleitos, o que implica os mesmos problemas citados anteriormente. Os próprios CONSADs refletem essa dificuldade, já que apenas oito consórcios, dos quarenta planejados inicialmente, se institucionalizaram enquanto consórcios públicos (ORTEGA, 2007).

\section{CONCLUSÃO E CONSIDERAÇÕES FINAIS}

Este trabalho abordou as principais inovações normativas e institucionais que o paradigma territorial trouxe para a ação de planejamento e implementação de políticas públicas no Brasil. Como essa temática ainda é relativamente nova no campo das políticas públicas e os programas analisados ainda estão em processo de consolidação, seria muito difícil apontar uma conclusão precisa, com base nos materiais disponíveis, sobre o questionamento aqui proposto. Mesmo assim, há um consenso, entre os estudiosos do tema, de que a abordagem territorial traz avanços significativos tanto no que se refere à visão anterior de desenvolvimento com base nas escalas macrorregionais brasileiras, que congregam uma realidade extremamente heterogênea para serem pensadas enquanto totalidade, quanto à visão es- 
sencialmente municipalista, dado que os municípios são instâncias muito numerosas, além de pequenas e com estrutura precária (em sua grande maioria).

Por outro lado, pôde-se constatar a persistência de alguns entraves para uma consolidação e institucionalização de fato da abordagem territorial no Brasil. Entre os principais deles estão: a dificuldade em estabelecer programas intersetoriais inovadores; a falta de um marco jurídico mais favorável para o desenvolvimento de programas territoriais de desenvolvimento, onde o território e seus respectivos fóruns deliberativos ganhem maior legitimidade; a necessidade de ações diferenciadas para o empoderamento de grupos sociais invisibilizados, dada a estrutura de desigualdade social no interior dos territórios brasileiros; os mecanismos de financiamento ainda são inadequados para darem suporte a projetos territoriais estratégicos; e o desprezo de temas importantes para o desenvolvimento territorial e que, a princípio, geram sérios conflitos de interesse, como a reforma agrária e a regularização fundiária, o que leva a crer que o processo de definição de projetos territoriais ocorre apenas sob um contexto harmônico de relação entre as forças sociais presentes, desconsiderando a existência de conflitos.

Esses entraves apontam que a temática territorial ainda não alcançou um nível de prioridade suficiente no campo da decisão política no país, embora apareça cada vez mais como diretriz dos programas governamentais. Entende-se com isso que a retórica discursiva presente nos documentos oficiais não foi acompanhada no mesmo ritmo por inovações normativas que a legitimem.

Todavia, deve-se deixar claro que as experiências em curso já desencadearam bons resultados, como a formação de novos arranjos institucionais para o planejamento e definição de prioridades para a ação governamental. O maior envolvimento dos atores sociais na gestão de políticas e pro- jetos territoriais pode ser considerado um ponto de partida importante para uma institucionalização mais forte no país de uma proposta dessa natureza.

\section{NOTAS}

1 Por atores sociais, entendem-se indivíduos ou organizações que realizam atividades ou mantêm relações sociais em um determinado território (SABOURIN, 2002).

${ }^{2}$ OPPA 2004-2007 estabeleceu uma estratégia de desenvolvimento de longo prazo fundamentada em três macro-objetivos decompostos em diversas diretrizes e desafios. Esses objetivos abrangem: i) inclusão social e redução das desigualdades sociais; ii) crescimento com geração de trabalho, emprego e renda, sob condições ambientais sustentáveis e redutoras das desigualdades sociais; e iii) promoção e expansão da cidadania e fortalecimento da democracia.

${ }^{3}$ No âmbito das orientações do governo federal para a elaboração de seus programas, a transversalidade é definida como "uma forma de atuação horizontal que busca construir políticas públicas integradas, por meio de ações articuladas" (BRASIL, 2007: p. 17). Para IPEA (2009: p. 780), a concepção de transversalidade "pressupõe atuação interdepartamental em que conhecimentos, recursos e técnicas acumuladas em cada espaço institucional possam atuar em sinergia".

${ }^{4}$ Para a Nova Economia Institucional (NEI), custos de transação referem-se à parcela do valor de uma negociação ou transação de valores econômicos que é apropriada por agentes diferentes daqueles que estão negociando, ou seja, é o valor apropriado por terceiros. Esses custos seriam, do modo mais formal, os custos de negociar, redigir e garantir que um contrato será cumprido.

5 O índice de Gini para a desigualdade de terra no Brasil registrado para 2006 foi de 0,854 , não muito diferente do índice para os anos de 1995 e 1985, que foram, respectivamente, 0,856 e 0,857 (SILVA, 2011). Um valor acima de 0,40 já é considerado um indicador de alta desigualdade.

\section{REFERÊNCIAS}

ABRAMOVAY, Ricardo. O futuro das regiões rurais. Porto Alegre: 2003.

ALVES, Roberto M. Dilemas e perspectivas da construção local e territorial do desenvolvimento sustentável e solidário. In: MACEDO, Miguel; PRAZERES, Maria A. B. (Orgs.) Democracia, transparência e desenvolvimento sustentável. Fortaleza: Fundação Konrad Adenauer, 2007. 
ARAÚJO, Tânia Bacelar. Brasil: desafios de uma política nacional de desenvolvimento regional contemporânea. In: DINIZ, Célio campolina. Políticas de desenvolvimento regional: desafios e perspectivas à luz das experiências da União Europeia e do Brasil. Brasília: UnB, 2007.

BANDEIRA, Pedro Silveira. As fronteiras nos processos de integração supranacional. In: DINIZ, Célio Campolina. Políticas de desenvolvimento regional: desafios e perspectivas à luz das experiências da União Europeia e do Brasil. Brasília: UnB, 2007.

BRANDÃO, Carlos. Territórios com classes sociais, conflitos, decisão e poder. In: ORTEGA, Antônio; FILHO, Niemeyer (Orgs.). Desenvolvimento territorial: segurança alimentar e economia solidária. Campinas: Alínea, 2007.

BRASIL. Referências para uma estratégia de desenvolvimento rural sustentável para o Brasil. Brasília: MDA/SDT, 2005.

Manual de avaliação do Plano Plurianual 2004-2007. Brasília: MP/SPIE, 2007.

CANDIOTTO, Luciano Z. Uma reflexão sobre ciência e conceitos: o território na geografia. In: Território e desenvolvimento: diferentes abordagens. Francisco Beltrão: Unioeste, 2004

COELHO, France M. G. A arte das orientações técnicas no campo: concepções e métodos. Viçosa: Editora UFV, 2005.

COELHO, Vera; FAVARETO, Arilson. Dilemas da participação e desenvolvimento territorial. In: DAGNINO, E.; TATAGIBA, L. (Orgs.) Sociedade civil e participação. Chapecó: Argos, 2007.

CORRÊA, Vanessa P. Desenvolvimento territorial e a implantação de políticas públicas brasileiras vinculadas a esta perspectiva. Boletim Regional, Urbano e Ambiental, nº 3, IPEA, 2009.

DAGNINO, Evelina. Sociedade civil e espaços públicos no Brasil. São Paulo: Paz e Terra, 2002.

FAVARETO, Arilson. Paradigmas do desenvolvimento rural em questão. São Paulo: FAPESP, 2007.

FERNANDES, Bernardo. Sobre a tipologia de territórios. In: SAQUET, Aurélio M.; SPOSITO, Eliseu S. (Orgs.) Territórios e territorialidades: teorias, processos e conflitos. São Paulo: Expressão Popular, 2009.

FLORES, Murilo. A identidade cultural do território como base de estratégias de desenvolvimento: uma visão do estado da arte. Projeto RIMISP, 2006.

FREITAS, Alan. Desenvolvimento territorial e inovações institucionais no Território Serra do Brigadeiro, Minas Gerais. Viçosa: UFV, 2011. Dissertação (Mestrado em Extensão Rural). Universidade Federal de Viçosa, 2011.

FURTADO, Celso. O Mito do Desenvolvimento Econômico. Rio de Janeiro: Paz e Terra, 1974.
Formação econômica do Brasil. São Paulo: Editora Nacional, 2003.

FURTADO, José Ribamar; FURTADO, Eliane Dayse. (R)evolução no desenvolvimento rural: território e mediação social. Brasília: IICA, 2004.

GHESTI, João Paulo. A abordagem territorial em políticas públicas: o caso do Território Águas Emendadas. Relatório de pesquisa. Planaltina: UNB, 2011.

GUANZIROLI, Carlos Enrique. Desenvolvimento territorial rural no Brasil: uma polêmica. In: Anais do Congresso da SOBER, Porto Alegre, 2009.

HAESBAERT, Rogério. O mito da desterritorialização: do fim dos territórios à multiterritorialidade. Rio de Janeiro: Bertrand Brasil, 2004.

HENRIQUES, Ricardo. Do olho do furacão. Democracia Viva, no 46, abril, 2011.

IPEA. Avanços e desafios da transversalidade nas políticas públicas federais voltadas para minorias. In: Brasil em desenvolvimento, v. 3. Brasília: IPEA, 2009.

JESUS, Clésio M. Desenvolvimento territorial no Brasil: experiência dos CONSADs. Dissertação (Mestrado em Economia). Universidade Federal de Uberlândia. Uberlândia, UFU, 2006.

KINGDON, John W. Agendas, alternatives and public policies. United States of America: Addison-Wesley Longman, 1995.

LEITE, Sérgio Pereira; DELGADO, Nelson Giordano; BONNAL, Philippe; KATO, Karina. Desenvolvimento territorial: articulação de políticas públicas e atores sociais. In: IICA. Articulação de políticas públicas e atores sociais. Brasília: IICA, 2008.

MALUF, Renato. Políticas agrícolas e de desenvolvimento rural e a segurança alimentar. In: LEITE, Sérgio (Org.) Politicas públicas e agricultura no Brasil. Porto Alegre: Ed. UFRGS, 2001.

MENDES, Constantino C. Brasil policêntrico e planejamento territorial de longo prazo. Parcerias Estratégicas, n. 26, 2008.

MILANI, Carlos R. S. O princípio da participação social na gestão de políticas públicas locais. Revista de Administração Pública, n. 42, v. 3, Rio de Janeiro, 2008.

MONTEIRO, Ana L. O. A relação Estado e sociedade civil no processo de formulação e implementação de políticas públicas: análise do Programa Nacional de DST e AIDS. Brasília, UnB, 2006. Dissertação (Mestrado em Gestão Social e Trabalho). Universidade de Brasília, 2006.

MORAES, Mario; LOURO, Sueli (Orgs.). Estudo sobre a nova estratégia de desenvolvimento regional. Erechim, RS: Edifapes, 2003.

ORTEGA, Antônio C. Desenvolvimento territorial rural no Brasil: 
limites e potencialidades dos CONSADs. Revista de Economia e Sociologia Rural, v. 45, n. 2, 2007.

ORTEGA, Antônio C.; JESUS, Clésio M. LIMA, Lucas F; MUNIZ, Andre L. Desenvolvimento territorial rural e consórcios intermunicipais: estudo de caso dos arranjos sócios produtivos induzidos em Minas Gerais. In: Anais do $47^{\circ}$ Congresso da SOBER, Porto Alegre, 2009.

PERICO, Rafael. Identidade e território no Brasil. Brasília: IICA, 2009.

RAFFESTIN, Claude. Por uma geografia do poder. São Paulo: Ática, 1993.

RODRIGUES, Melania P. Gestão social do território: experiências no estado do Maranhão. Brasília: IICA, 2005.

ROVER, Oscar. Obstáculos e exigências para a governança regional. Revista Brasileira de Gestão e Desenvolvimento Regional, v. 7, n. 1, 2011.

SABOURIN, Eric. Desenvolvimento rural e abordagem territorial: conceitos, estratégias e atores. In: SABOURIN, Eric; TEIXEIRA, Olívio A. (Orgs.) Planejamento e desenvolvimento dos territórios rurais. Brasília: Embrapa, 2002.
SACK, Robert. Human territoriality. Cambridge: Cambridge University Press, 1986.

SANTOS, Milton. O espaço dividido: os dois circuitos da economia urbana dos países subdesenvolvidos. São Paulo: Hucitec, 1978.

1997.

Metamorfoses do espaço habitado. São Paulo: Hucitec,

SANTOS, Milton; SILVEIRA, Maria Laura. O Brasil: território e sociedade no início do século XXI. São Paulo: Record, 2001.

SARACENO, Elena. Las políticas de desarrollo rural em los procesos de modernización. In: Seminário Nacional de Desenvolvimento Rural Sustentável. Brasília, 23-25 de agosto de 2005 .

SILVA, Sandro Pereira. Políticas públicas, agricultura familiar e desenvolvimento territorial. Cadernos Gestão Pública e Cidadania, v. 16, n. $58,2011$.

Politicas públicas e agricultura familiar: uma abordagem territorial do PRONAF no Médio Jequitinhonha. Viçosa: UFV, 2008. Dissertação (Mestrado em Economia) Universidade Federal de Viçosa, 2008. 